\title{
Background Parenchymal Enhancement on Breast MRI: Assessment and Clinical Implications
}

\author{
James S. Chalfant ${ }^{1}\left(\mathbb{D} \cdot\right.$ Shabnam Mortazavi $^{1} \cdot$ Stephanie A. Lee-Felker $^{1}$
}

Accepted: 6 September 2021 / Published online: 27 September 2021

(C) The Author(s) 2021

\begin{abstract}
Purpose of Review To present recent literature regarding the assessment and clinical implications of background parenchymal enhancement on breast MRI.

Recent Findings The qualitative assessment of BPE remains variable within the literature, as well as in clinical practice. Several different quantitative approaches have been investigated in recent years, most commonly region of interest-based and segmentation-based assessments. However, quantitative assessment has not become standard in clinical practice to date. Numerous studies have demonstrated a clear association between higher BPE and future breast cancer risk. While higher BPE does not appear to significantly impact cancer detection, it may result in a higher abnormal interpretation rate. BPE is also likely a marker of pathologic complete response after neoadjuvant chemotherapy, with decreases in BPE during and after neoadjuvant chemotherapy correlated with pCR. In contrast, pre-treatment BPE does not appear to be predictive of pCR. The association between BPE and prognosis is less clear, with heterogeneous results in the literature.

Summary Assessment of BPE continues to evolve, with heterogeneity in approaches to both qualitative and quantitative assessment. The level of BPE has important clinical implications, with associations with future breast cancer risk and treatment response. BPE may also be an imaging
\end{abstract}

This article is part of the Topical collection on Breast Imaging.

James S. Chalfant

jchalfant@mednet.ucla.edu

1 Department of Radiological Sciences, David Geffen School of Medicine at University of California, Los Angeles, 1250 16th Street, Suite 2340, Santa Monica, CA 90404, USA marker of prognosis, but future research is needed on this topic.

Keywords Background parenchymal enhancement . Breast MRI - Breast cancer - Breast cancer risk · Treatment response $\cdot$ Breast cancer prognosis

\section{Introduction}

Although the normal enhancement of breast parenchyma on breast MRI has been appreciated for many years, the clinical implications of this enhancement have only become evident more recently. Reporting of this normal enhancement, termed "background parenchymal enhancement" (BPE), was standardized in 2013 as part of the American College of Radiology (ACR) Breast Imaging Reporting and Data System (BI-RADS) Atlas (fifth edition) when the original MRI lexicon was revised. Since that time, there has been a substantial increase in publications related to BPE. The purpose of this review is to update the reader on the literature published in the last five years, with a particular focus on the assessment and clinical implications of BPE.

\section{Overview}

BPE refers to the normal enhancement of the breast fibroglandular tissue. According to the fifth edition of the ACR BI-RADS Atlas, it should be assessed on the first post-contrast image at approximately $90 \mathrm{~s}$, as this is the time point at which cancer detection is typically performed. BPE is evaluated with respect to the amount of 
fibroglandular tissue (not breast volume) and is to be reported as minimal, mild, moderate, or marked [1] (Figs. 1, 2).

BPE will most commonly be diffuse and symmetric. More peripheral enhancement, or "picture framing," can also be seen (Fig. 3) and has been attributed to the arterial vascular supply of the breast, which enters the breast peripherally [2]. Asymmetric BPE should be reported when present, as is often seen after breast conservation therapy with radiation therapy [3] (Fig. 4). While different distributions and morphologies of enhancement have been explored in the prior literature [4, 5], BPE assessment currently is based on the volume and intensity of enhancement only and does not account for distribution or morphology [1].

Earlier studies suggested that BPE varied with the menstrual cycle $[4,6,7]$, leading to the recommendation that non-urgent breast MRI be performed early in the menstrual cycle (typically the second week) [1]. However, a few recent studies, including studies by Lee et al. (1536 screening MRI examinations) and Dontchos et al. (320 screening MRI examinations), have demonstrated no significant difference in screening MRI BPE by week of the menstrual cycle $[8,9 \bullet, 10 \bullet]$. More importantly, these studies did not demonstrate a difference in performance metrics (such as abnormal interpretation rate, cancer detection rate, sensitivity, specificity) by week of the
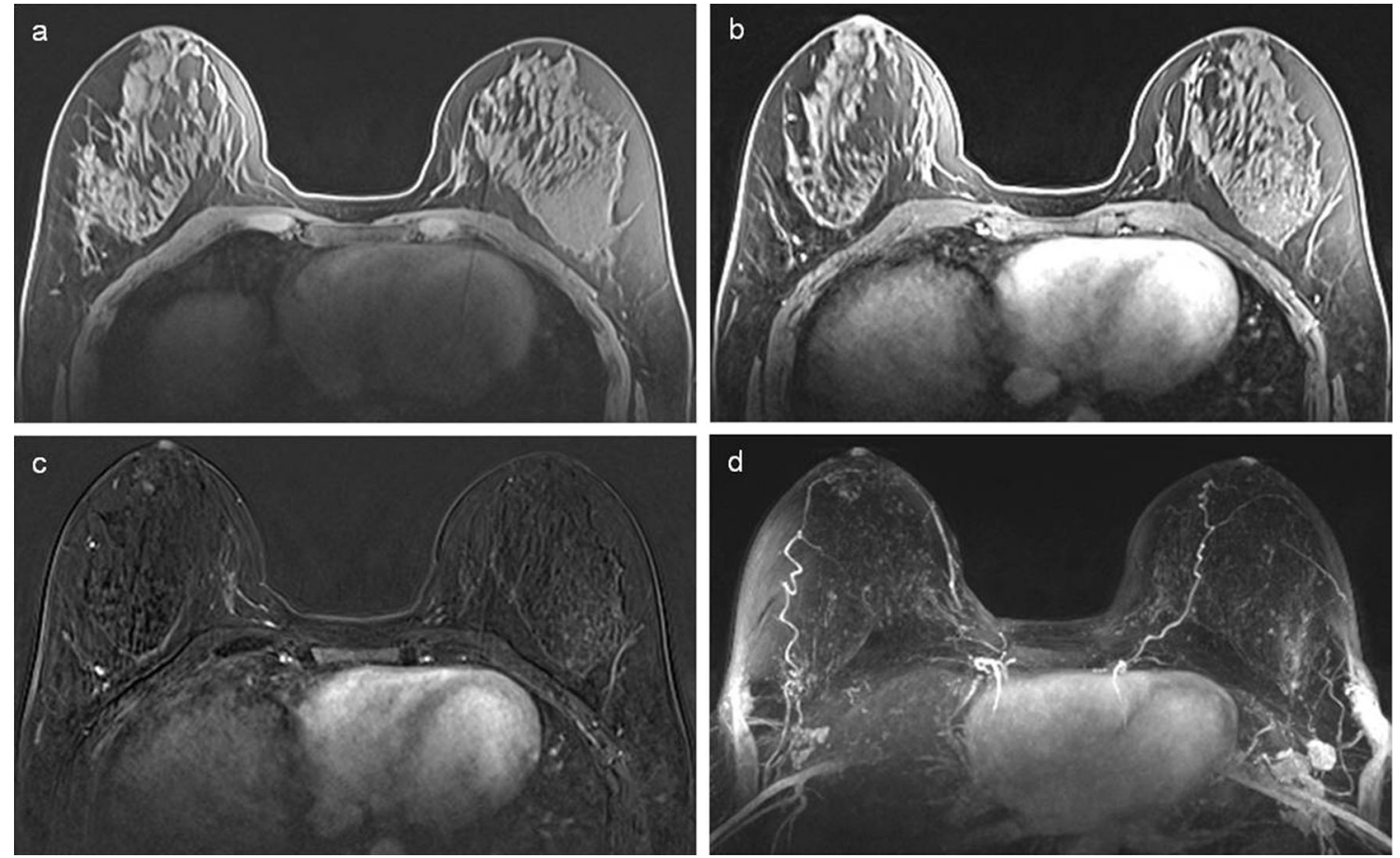

Fig. 1 a Axial unenhanced T1-weighted fat-suppressed, b axial contrast-enhanced T1-weighted fat-suppressed, c axial contrastenhanced T1-weighted fat-suppressed subtraction, and d axial menstrual cycle. As such, the timing of breast MRI screening studies may not be as relevant as previously thought.

A comprehensive discussion of other patient characteristics influencing BPE is beyond the scope of this review, but a few factors warrant mention, given that they are routinely encountered in clinical practice. Younger age and premenopausal status have both been shown to be associated with higher BPE [11-13], as has a higher body mass index (BMI) [11, 14]. BPE is also affected by exogenous hormone therapies. Hormone replacement therapy has been shown to increase BPE, while the anti-estrogen effects of aromatase inhibitors and selective estrogen receptor modulators used in endocrine therapy for breast cancer have been shown to decrease BPE. The cessation of tamoxifen (a selective estrogen receptor modulator) can result in focal or global "rebound" in BPE [2], which may lead to a diagnostic dilemma if this history is not known. Focal rebound in BPE can be particularly challenging to interpret. Adjuvant chemotherapy has also been shown to decrease BPE [15]. Finally, it has been shown that radiation therapy after breast conservation surgery and prophylactic breast irradiation in high risk populations reduce BPE [16, 17]. However, this reduction may not be seen in all patients with a history of breast radiation exposure, as Zeng et al. reported that patient's with a history of chest radiation for childhood or early adulthood Hodgkin's lymphoma had contrast-enhanced T1-weighted fat-suppressed subtraction MIP MR images demonstrating an example of mild BPE 

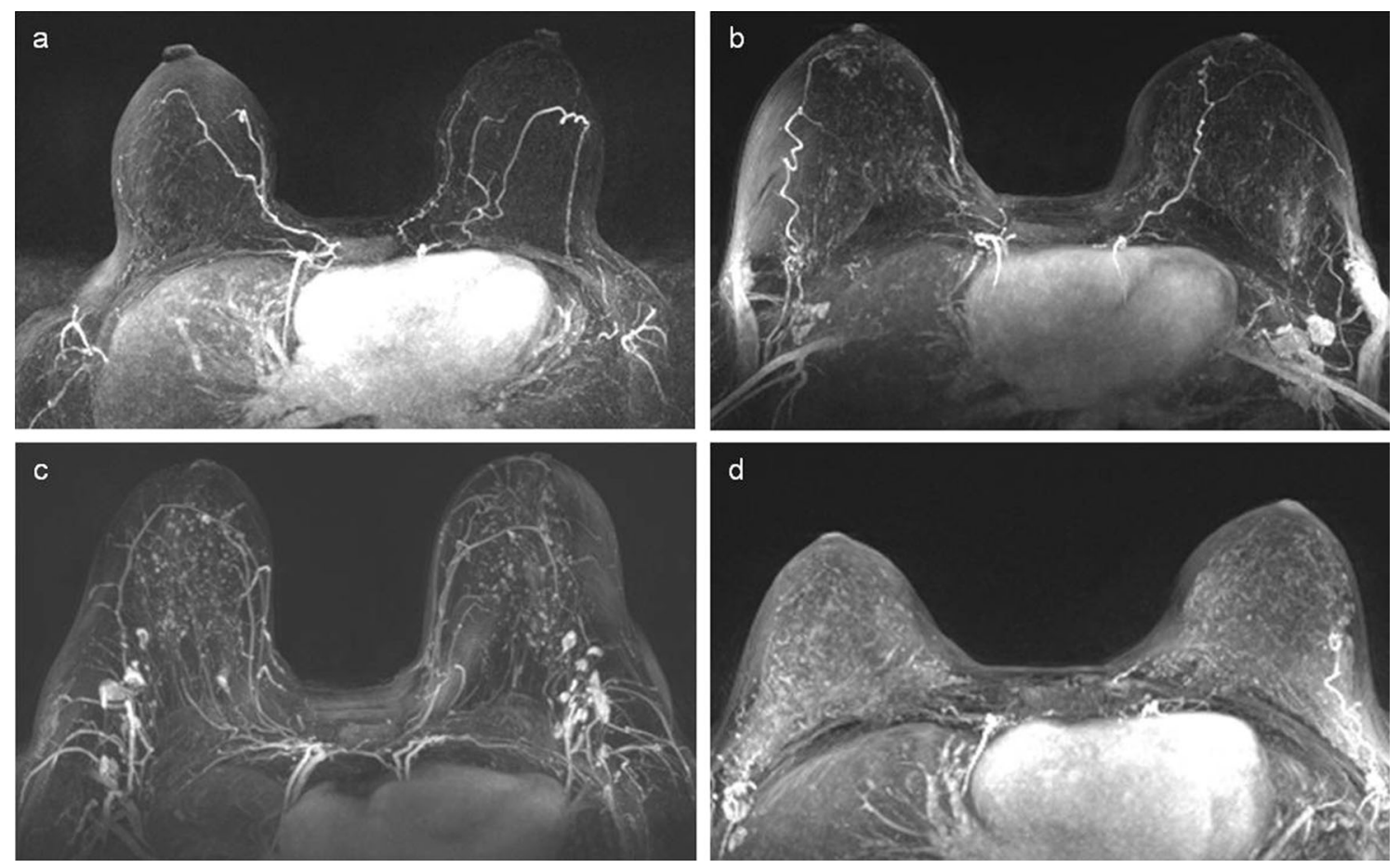

Fig. 2 a Minimal, b mild, c moderate, and $\mathbf{d}$ marked BPE on axial contrast-enhanced T1-weighted fat-suppressed subtraction MIP MR images

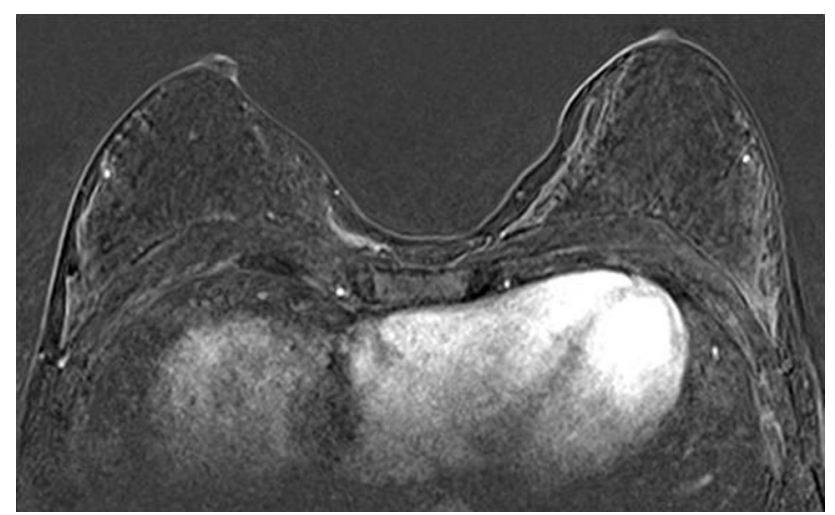

Fig. 3 Axial contrast-enhanced T1-weighted fat-suppressed subtraction MR image demonstrating a peripheral "picture framing" BPE pattern

higher BPE than age-matched controls when undergoing screening breast MRI years later [18].

\section{Qualitative Assessment}

Despite standardization of BPE reporting in the BI-RADS lexicon, there is variability in the methods used by radiologists to qualitatively assess BPE. In a 2017 systematic review by Bignotti et al., 16 of 39 studies qualitatively assessed BPE using a combination of unenhanced and contrast-enhanced fat-suppressed T1-weighted and subtraction images, 5 of 39 added maximum intensity

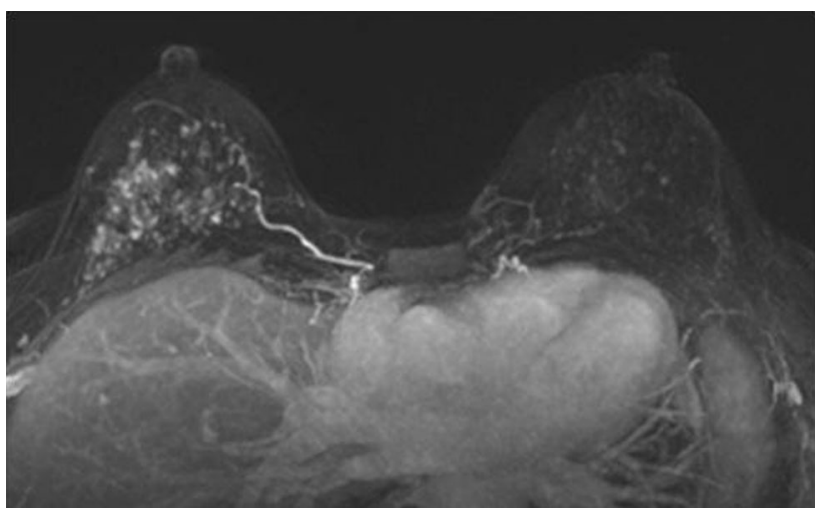

Fig. 4 Axial contrast-enhanced T1-weighted fat-suppressed subtraction MIP MR image demonstrating asymmetric BPE in a patient with history of breast conservation surgery status post radiation therapy

projection (MIP) images to this assessment, 14 of 39 used a combination of post-contrast fat-suppressed $\mathrm{T} 1$ weighted and/or subtraction images, and 1 of 39 used only MIP images ( 3 of 39 did not clearly state the assessment technique used) [19].

Separately, one study demonstrated that the combination of the initial contrast-enhanced fat-suppressed T1-weighted images, initial contrast-enhanced subtraction images, and initial contrast-enhanced MIP image has the highest reliability for assessing BPE (Gwet's AC1 value 0.80 [95\% confidence interval 0.77-0.84] and absolute agreement of $91.8 \%$ among three readers) (62). However, using the MIP image alone showed similar reliability (Gwet's AC1 value 
0.80 [95\% confidence interval $0.76-0.83]$ and absolute agreement of $92.4 \%$ ) and lower reading time ( $4 \mathrm{~s}$ for MIP alone versus $38 \mathrm{~s}$ ) [20]. Despite being an uncommon methodology in the literature, using the MIP image alone for BPE assessment may be a useful time-saving step in clinical practice.

The subjective nature of qualitative assessment also results in intra-reader and inter-reader variability. Kappa values for intra-reader agreement range from moderate to almost perfect in prior literature, while Kappa values for inter-reader agreement range from fair to almost perfect [19].

\section{Quantitative Assessment}

The fifth edition of the BI-RADS Atlas recommends a visual estimation of BPE, stating "categorizing based on percentages (and specifically into quartiles) is not recommended. Quantification of BPE volume and intensity on MRI may be feasible in the future, but we await publication of robust data on that topic before endorsing percentage recommendations" [1]. Several different quantitative approaches have been investigated since the publication of the fifth edition of the BI-RADS Atlas, with numerous studies in the past five years [21-34].

Region of interest-based and segmentation-based assessments are the two most common approaches in the recent literature. Generally, region of interest-based approaches still rely on user input, leading to potential reader variability. Segmentation-based assessments attempt to address this issue by isolating the fibroglandular tissue from the remaining tissues and assessing the entire fibroglandular volume rather than a region of interest. Various semi-automated and automated segmentation models have been created [27-30]. BPE assessment tools using machine learning have also been developed [31-34]. Overall, many of these approaches have correlated well with qualitative BPE assessment. However, despite this progress, quantitative assessment has not become standard in clinical practice to date.

\section{BPE on Emerging MRI Protocols}

Ultrafast MRI protocols consist of multiple high temporal resolution images after contrast injection, acquiring enhancement data prior to the first post-contrast sequence in standard protocols. One of the potential benefits of ultrafast MRI protocols is less prominent BPE at these early time points. Tomida et al. showed that there is almost no BPE during the "super early phase" (20 s after contrast injection) [35]. Honda et al. found that BPE was lower on the twelfth and twentieth phases of a $75 \mathrm{~s}$ ultrafast protocol compared to the first post-contrast phase of conventional dynamic contrast-enhanced MRI, with higher lesion detectability at the ultrafast protocol time points in patients with higher BPE at the conventional MRI time point [36]. Other studies have also demonstrated higher lesion conspicuity in cases with moderate or marked BPE [37, 38].

Abbreviated protocol MRIs have also been a focus in recent years due to their potential benefits of lower acquisition time, interpretation time, and cost. Abbreviated protocols vary but usually include at least an unenhanced and first post-contrast sequence, providing only morphologic information without kinetic assessment. While these protocols are promising, one study showed moderate or marked BPE lowered the rate of concordance between MRI measurements and pathology measurements for the maximum extent of ductal carcinoma in situ (DCIS) [39]. More research is needed to determine the impact of BPE on abbreviated protocols.

\section{Clinical Implications}

\section{Breast Cancer Risk}

Numerous studies have now identified an association between BPE and breast cancer risk. The Imaging and Epidemiology (IMAGINE) case-control study with 835 breast cancer cases and 963 controls demonstrated an association between moderate or marked BPE and premenopausal cancer after adjusting for breast density and other risk factors and confounders (OR 1.49); a similar but non-significant association was seen between mild, moderate, or marked BPE and postmenopausal cancer (OR 1.45) [40 ${ }^{\bullet}$. A retrospective study by Arasu et al. assessed 4247 women imaged at one of 46 radiology facilities within the Breast Cancer Surveillance Consortium. 176 developed breast cancer, with increasing BPE levels associated with increased cancer risk. This association was independent of breast density. Mild, moderate, or marked BPE also demonstrated a significant increased risk of invasive cancer (hazard ratio 2.73) [41•]. These results are corroborated by a recent meta-analysis of 13 studies (13,788 patients with 4,046 breast cancer cases) showing that moderate BPE and marked BPE were associated with an elevated risk of breast cancer (OR 2.66 and 2.51, respectively) [42]; a separate meta-analysis of 12 studies (9541 patients with 3870 breast cancer cases) showed similar results (moderate BPE OR 2.93 and marked BPE OR 2.89) [43]. Studies have demonstrated this association using both qualitative and quantitative BPE assessments. Saha et al. demonstrated that quantitative BPE assessment using machine learning models can be predictive of the 
subsequent development of breast cancer independent of qualitative BPE assessment [44].

In addition, a meta-analysis by Thompson et al. analyzing 18 studies (1910 breast cancer cases and 2541 controls) found that higher levels of BPE were associated with the presence of breast cancer in women with an elevated lifetime risk of breast cancer, but not in women with average lifetime risk of breast cancer [45•]. It is important to note that data on women considered to be at average lifetime risk is somewhat limited, as screening MRI is not typically performed in this patient population (and therefore most available data is in the setting of symptoms, suspicious imaging findings, or known malignancy). For women with an elevated lifetime risk, this increased risk may be present even for mild BPE [45, 46]. This future risk of breast cancer relative to lower BPE levels has also been shown to persist in women with elevated lifetime risk after risk-reducing salpingo-oophorectomy, suggesting BPE is not merely a surrogate marker for endogenous hormone levels [47, 48]. Moderate to marked BPE has also been associated with the development of interval cancers in patients with a personal history of breast cancer [49].

Further evidence of the association between BPE and breast cancer may come from its link to obesity. There is evidence that higher BMI is a risk factor for at least postmenopausal breast cancer [50], and, as discussed earlier, higher BMI has been shown to be associated with higher BPE [11, 14]. More specifically, visceral adipose tissue has been identified as a risk factor for numerous disease processes, including breast cancer, and has had many of its endocrine functions and pro-inflammatory roles linked to disease pathogenesis [51]. Brown et al. demonstrated that, while several body composition measures including BMI correlated with BPE prior to an exercise intervention, only reductions in visceral adipose tissue correlated with a decrease in BPE after exercise intervention [52]. This association between visceral adipose tissue and BPE further supports the available data suggesting BPE may serve as an imaging marker of future breast cancer risk.

BPE has also been associated with breast metabolic activity, correlating with FDG uptake on PET [53-56]. Mema et al. hypothesized that the increased breast cancer risk associated with higher BPE could be due to this elevated basal metabolic activity, resulting in an environment for tumor growth [54].

\section{Cancer Detection, Extent of Disease Assessment, and Margin Status}

Several recent studies have shown that BPE does not influence cancer detection rate $[57 \bullet, 58,59 \bullet]$, although moderate or marked BPE may be associated with higher abnormal interpretation rates [57•, 59•]. Higher biopsy rates and lower specificity have also been noted $[59 \bullet, 60]$. Similarly, studies have shown that BPE in the lactating breast, which is often moderate or marked, does not prevent cancer detection [61, 62].

Recent data regarding the impact of BPE on extent of disease measurements and margin status is more heterogeneous. Two studies have shown no association between $\mathrm{BPE}$ and positive margins or need for repeat surgeries for invasive lobular carcinoma [63, 64]. However, other studies have reported an association between higher BPE and positive or close $(<2 \mathrm{~mm})$ margins in breast conserving surgeries for invasive ductal carcinoma [65, 66]. BPE also has been reported to negatively influence diagnostic performance in the evaluation for residual malignancy after excisional biopsy for microcalcifications [67]. In addition, two recent studies have shown that tumor size measurement may be more accurate in cases with minimal or mild BPE [68, 69], although a third study assessing pure DCIS cases found that BPE did not influence size measurements [58]. Further research is needed to determine whether BPE does in fact impact tumor size measurements in a clinically significant way.

\section{Treatment Response}

Several studies have investigated $\mathrm{BPE}$ as a potential predictor of neoadjuvant chemotherapy (NAC) response. A systemic review of 22 articles found that a greater decrease in BPE in the disease-free contralateral breast during and after NAC was associated with pathologic complete response (pCR) [70•]. In individual studies, a low lesion-tobackground parenchymal signal enhancement ratio (SER) post-NAC has also been associated with pCR [71, 72]. This association between a reduction in $\mathrm{BPE}$ and $\mathrm{pCR}$ has been seen for both human epidermal growth factor receptor 2 (HER2) positive and HER2 negative cancers [73-75]. You et al. assessed BPE at multiple treatment time points (after the second, fourth, and sixth cycles of NAC) and showed that the decrease in BPE from baseline after the second cycle of NAC had the most diagnostic value in predicting pCR [75].

Identifying imaging markers predictive of treatment response prior to the start of therapy would be even more beneficial. Unfortunately, most studies have found no correlation between pre-treatment BPE and pCR [74, 76-78], with a minority suggesting a link between pretreatment BPE and pCR [79].

\section{Prognosis}

There is some heterogeneity in the recent literature with respect to the relationship between BPE and prognosis. 
BPE in the contralateral breast has been associated with the tumor Oncotype Dx recurrence score [80]. BPE has been correlated with locoregional recurrence [81], and moderate or marked BPE correlated with late recurrence $(>2.5$ years after surgery) [82]. Lesion peak SER and mean BPE have also been correlated with DCIS recurrence [83]. In addition, Choi et al. showed moderate or marked BPE on preNAC MRI was independently associated with worse recurrence-free survival [84], while Lim et al. showed an association between non-minimal BPE and worse recurrence-free survival in postmenopausal women [66]. In contrast, two recent studies have shown no correlation with recurrence [85, 86]. Another study evaluated BPE qualitatively and quantitatively before and after NAC and found that only post-therapeutic quantitative BPE predicted recurrence [77]. In a systemic review by Rella et al., no significant association was found between BPE and invasiveness, histological cancer type, T- and N-stage, multifocality, lymphatic and vascular invasion, and histological tumor grade [70•].

This variability in the literature may in part be explained by the heterogeneous nature of breast cancer. Molecular subtypes of breast cancer play an important role in prognosis [87], but the interrelationships between BPE, molecular subtype, and prognosis are unclear. Studies have suggested that moderate or marked BPE is associated with an increased rate of estrogen receptor (ER) positive and progesterone receptor (PR) positive cancers [88, 89], while minimal or mild BPE may be more frequently associated with triple negative breast cancers [90]. Quantitative image features of BPE have also shown some promise in differentiating molecular subtypes [91]. One recent study by $\mathrm{Xu}$ et al. demonstrated that, while pre-operative BPE in the disease-free contralateral breast did not correlate with overall survival or invasive disease-free survival for the overall cohort of 467 patients, moderate or marked BPE correlated with overall survival and invasive disease-free survival in a subset of 127 triple negative breast cancer cases who received adjuvant chemotherapy [92]. Park et al. demonstrated that higher SER around the tumor on preoperative MRI independently predicted recurrence in triple negative breast cancer patients [93]. With respect to ER positive HER2 negative invasive cancers, one study showed no association with survival outcome in 289 patients with ER positive HER2 negative node negative invasive cancers [94], while another including 398 patients ER positive HER2 negative invasive cancers showed improved overall survival [95].

\section{Conclusions}

There has been considerable interest in BPE in the recent literature, and it is now evident that BPE has diverse clinical implications. Numerous studies have demonstrated a clear association between higher BPE and future breast cancer risk, and BPE may be an important imaging marker for risk stratification in the era of personalized medicine. While higher BPE does not appear to significantly impact cancer detection, it may result in a higher abnormal interpretation rate. BPE is also likely predictive of treatment response, with reductions in BPE during and after NAC correlated with pCR. However, most studies have found no correlation between BPE before NAC and pCR. The association between BPE and prognosis is less clear. Given the heterogeneous nature of breast cancer, BPE is unlikely to be a one-size-fits-all prognostic imaging marker. As such, further research is needed on BPE in breast cancer subtypes and population subsets, including women who are otherwise considered to be at average lifetime risk of breast cancer.

Progress has been made in the quantitative assessment of BPE, a topic specifically mentioned as one for further research in the fifth edition of the BI-RADS Atlas, although this has yet to make its way into routine clinical practice. However, although the BPE lexicon is standardized in the BI-RADS Atlas, variability remains in the approaches to both qualitative and quantitative BPE assessment, hampering the comparison of studies. Future research would benefit from standardized methodologies.

Funding None.

Data availability Not applicable.

Code availability Not applicable.

\section{Declarations}

Conflict of interest The authors have no conflicts of interest.

Animal rights This article does not contain any studies with human or animal subjects performed by any of the authors.

Open Access This article is licensed under a Creative Commons Attribution 4.0 International License, which permits use, sharing, adaptation, distribution and reproduction in any medium or format, as long as you give appropriate credit to the original author(s) and the source, provide a link to the Creative Commons licence, and indicate if changes were made. The images or other third party material in this article are included in the article's Creative Commons licence, unless indicated otherwise in a credit line to the material. If material is not included in the article's Creative Commons licence and your intended 
use is not permitted by statutory regulation or exceeds the permitted use, you will need to obtain permission directly from the copyright holder. To view a copy of this licence, visit http://creativecommons. org/licenses/by/4.0/.

\section{References}

Papers of particular interest, published recently, have been highlighted as:

- Of importance

1. Morris EA, Comstock CE, Lee $\mathrm{CH}$, et al. ACR BI-RADS ${ }^{\circledR}$ Magnetic Resonance Imaging. In: ACR BI-RADS ${ }^{\circledR}$ Atlas, Breast Imaging Reporting and Data System. Reston, VA: American College of Radiology; 2013.

2. Giess CS, Yeh ED, Raza S, Birdwell RL. Background parenchymal enhancement at breast MR imaging: normal patterns, diagnostic challenges, and potential for false-positive and false-negative interpretation. Radiographics. 2014;34(1):234-47. https://doi.org/10.1148/rg.341135034.

3. Li J, Dershaw DD, Lee CH, Joo S, Morris EA. Breast MRI after conservation therapy: usual findings in routine follow-up examinations. AJR Am J Roentgenol. 2010;195(3):799-807. https:// doi.org/10.2214/AJR.10.4305.

4. Kuhl CK, Bieling HB, Gieseke J, Kreft BP, Sommer T, Lutterbey G, Schild HH. Healthy premenopausal breast parenchyma in dynamic contrast-enhanced MR imaging of the breast: normal contrast medium enhancement and cyclical-phase dependency. Radiology. 1997;203(1):137-44. https://doi.org/10.1148/radiology.203.1. 9122382.

5. Jansen SA, Lin VC, Giger ML, Li H, Karczmar GS, Newstead GM. Normal parenchymal enhancement patterns in women undergoing MR screening of the breast. Eur Radiol. 2011;21(7):1374-82. https://doi.org/10.1007/s00330-011-2080-z.

6. Müller-Schimpfle M, Ohmenhaüser K, Stoll P, Dietz K, Claussen CD. Menstrual cycle and age: influence on parenchymal contrast medium enhancement in MR imaging of the breast. Radiology. 1997;203(1):145-9. https://doi.org/10.1148/radiology.203.1.9122383.

7. Delille JP, Slanetz PJ, Yeh ED, Kopans DB, Garrido L. Physiologic changes in breast magnetic resonance imaging during the menstrual cycle: perfusion imaging, signal enhancement, and influence of the T1 relaxation time of breast tissue. Breast J. 2005;11(4):236-41. https://doi.org/10.1111/j.1075-122X.2005.21499.x.

8. de Kermadec E, Thomassin I, Daraï E, Kolanska K, ChabbertBuffet N. Impact of the menstrual cycle on the quality of interpretation of the MRI result in the follow-up of women at genetic risk for breast. Gynecol Obstet Fertil Senol. 2021. https://doi.org/ 10.1016/j.gofs.2021.03.024.

9. •Lee CH, Bryce Y, Zheng J, Sung JS, Comstock CE, Moskowitz C, Morris AE. Outcome of Screening MRI in Premenopausal Women as a Function of the Week of the Menstrual Cycle. AJR Am J Roentgenol. 2020;214(5):1175-1181. https://doi.org/10. 2214/AJR.18.19960. This study found no difference in BPE levels or performance metrics of screening MRI by week of the menstrual cycle during which the MRI was performed.

10. •Dontchos BN, Rahbar H, Partridge SC, Lehman CD, DeMartini WB. Influence of menstrual cycle timing on screening breast MRI background parenchymal enhancement and diagnostic performance in premenopausal women. $\mathrm{J}$ Breast Imaging. 2019;1(3):205-211. doi: https://doi.org/10.1093/jbi/wbz022. This study found no difference in BPE levels or performance metrics of screening MRI by menstrual cycle phase or week
11. Hellgren R, Saracco A, Strand F, Eriksson M, Sundbom A, Hall P, Dickman PW. The association between breast cancer risk factors and background parenchymal enhancement at dynamic contrast-enhanced breast MRI. Acta Radiol. 2020;61(12):1600-7. https://doi.org/10.1177/0284185120911583.

12. Li J, Mo Y, He B, Gao Q, Luo C, Peng C, Zhao W, Ma Y, Yang Y. Association between MRI background parenchymal enhancement and lymphovascular invasion and estrogen receptor status in invasive breast cancer. $\mathrm{Br} \mathrm{J}$ Radiol. 2019;92(1103):20190417. https://doi.org/10.1259/bjr.20190417.

13. Arslan G, Çelik L, Çubuk R, Çelik L, Atasoy MM. Background parenchymal enhancement: is it just an innocent effect of estrogen on the breast? Diagn Interv Radiol. 2017;23(6):414-9. https://doi.org/10.5152/dir.2017.17048.

14. Gillman J, Chun J, Schwartz S, Schnabel F, Moy L. The relationship of obesity, mammographic breast density, and magnetic resonance imaging in patients with breast cancer. Clin Imaging. 2016;40(6):1167-72. https://doi.org/10.1016/j.clinimag.2016.08. 009.

15. Kim EJ, Kang BJ, Kim SH, Youn IK, Baek JE, Lee HS. Diagnostic performance of and breast tissue changes at early breast MR imaging surveillance in women after breast conservation therapy. Radiology. 2017;284(3):656-66. https://doi.org/10.1148/ radiol.2017162123.

16. Kim YJ, Kim SH, Choi BG, Kang BJ, Kim HS, Cha ES, Song BJ. Impact of radiotherapy on background parenchymal enhancement in breast magnetic resonance imaging. Asian Pac J Cancer Prev. 2014;15(7):2939-43. https://doi.org/10.7314/apjcp.2014.15.7.2939.

17. Ben-David MA, Corn BW, Evron E, Goldberg H, Pfeffer RM, Abdah-Bortnyak R, Matceyevsky D, Weinstein Y, Golan O, Sklair-Levy M. Prophylactic breast irradiation reduces background parenchymal enhancement (BPE) on MRI: a secondary analysis. Breast. 2020;49:70-3. https://doi.org/10.1016/j.breast. 2019.10.011.

18. Zeng L, Lo G, Moshonov H, Liang J, Hodgson D, Crystal P. Breast background parenchymal enhancement on screening magnetic resonance imaging in women who received chest radiotherapy for childhood hodgkin's lymphoma. Acad Radiol. 2016;23(2):168-75. https://doi.org/10.1016/j.acra.2015.09.010.

19. Bignotti B, Signori A, Valdora F, Rossi F, Calabrese M, Durando M, Mariscotto G, Tagliafico A. Evaluation of background parenchymal enhancement on breast MRI: a systematic review. Br J Radiol. 2017;90(1070):20160542. https://doi.org/10.1259/ bjr.20160542.

20. Bignotti B, Calabrese M, Signori A, Tosto S, Valdora F, Tagliafico A, Durando M, Mariscotti G. Background parenchymal enhancement assessment: inter- and intra-rater reliability across breast MRI sequences. Eur J Radiol. 2019;114:57-61. https://doi. org/10.1016/j.ejrad.2019.02.036.

21. Wei D, Jahani N, Cohen E, Weinstein S, Hsieh MK, Pantalone L, Kontos D. Fully automatic quantification of fibroglandular tissue and background parenchymal enhancement with accurate implementation for axial and sagittal breast MRI protocols. Med Phys. 2021;48(1):238-52. https://doi.org/10.1002/mp.14581.

22. Nguyen AA, Arasu VA, Strand F, Li W, Onishi N, Gibbs J, Jones EF, Joe BN, Esserman LJ, Newitt DC, Hylton NM. Comparison of segmentation methods in assessing background parenchymal enhancement as a biomarker for response to neoadjuvant therapy. Tomography. 2020;6(2):101-10. https://doi.org/10.18383/j.tom. 2020.00009 .

23. van der Velden BHM, van Rijssel MJ, Lena B, Philippens MEP, Loo CE, Ragusi MAA, Elias SG, Sutton EJ, Morris EA, Bartels LW, Gilhuijs KGA. Harmonization of quantitative parenchymal enhancement in $\mathrm{T}_{1}$-weighted breast MRI. J Magn Reson Imaging. 2020;52(5):1374-82. https://doi.org/10.1002/jmri.27244. 
24. Losurdo L, Basile TMA, Fanizzi A, Bellotti R, Bottigli U, Carbonara R, Dentamaro R, Diacono D, Didonna V, Lombardi A, Giotta F, Guaragnella C, Mangia A, Massafra R, Tamborra P, Tangaro S, La Forgia D. A gradient-based approach for breast DCE-MRI analysis. Biomed Res Int. 2018;16(2018):9032408. https://doi.org/10.1155/2018/9032408.

25. Amano Y, Woo J, Amano M, Yanagisawa F, Yamamoto H, Tani M. MRI texture analysis of background parenchymal enhancement of the breast. Biomed Res Int. 2017;2017:4845909. https:// doi.org/10.1155/2017/4845909.

26. Ha R, Mema E, Guo X, Mango V, Desperito E, Ha J, Wynn R, Zhao B. Three-dimensional quantitative validation of breast magnetic resonance imaging background parenchymal enhancement assessments. Curr Probl Diagn Radiol. 2016;45(5):297-303. https://doi.org/10.1067/j.cpradiol.2016.02.003.

27. Ma X, Wang J, Zheng X, Liu Z, Long W, Zhang Y, Wei J, Lu Y. Automated fibroglandular tissue segmentation in breast MRI using generative adversarial networks. Phys Med Biol. 2020;65(10):105006. https://doi.org/10.1088/1361-6560/ab7e7f.

28. Fashandi H, Kuling G, Lu Y, Wu H, Martel AL. An investigation of the effect of fat suppression and dimensionality on the accuracy of breast MRI segmentation using U-nets. Med Phys. 2019;46(3):1230-44. https://doi.org/10.1002/mp.13375.

29. Veeraraghavan H, Dashevsky BZ, Onishi N, Sadinski M, Morris E, Deasy JO, Sutton EJ. Appearance constrained semi-automatic segmentation from DCE-MRI is reproducible and feasible for breast cancer radiomics: a feasibility study. Sci Rep. 2018;8(1):4838. https://doi.org/10.1038/s41598-018-22980-9.

30. Jiang L, Hu X, Xiao Q, Gu Y, Li Q. Fully automated segmentation of whole breast using dynamic programming in dynamic contrast-enhanced MR images. Med Phys. 2017;44(6):2400-14. https://doi.org/10.1002/mp.12254.

31. Nam Y, Park GE, Kang J, Kim SH. Fully automatic assessment of background parenchymal enhancement on breast MRI using machine-learning models. J Magn Reson Imaging. 2021;53(3):818-26. https://doi.org/10.1002/jmri.27429.

32. Borkowski K, Rossi C, Ciritsis A, Marcon M, Hejduk P, Stieb S, Boss A, Berger N. Fully automatic classification of breast MRI background parenchymal enhancement using a transfer learning approach. Medicine (Baltimore). 2020;99(29):e21243. https://doi. org/10.1097/MD.0000000000021243.

33. Xu X, Fu L, Chen Y, Larsson R, Zhang D, Suo S, Hua J, Zhao J. Breast region segmentation being convolutional neural network in dynamic contrast enhanced MRI. Annu Int Conf IEEE Eng Med Biol Soc. 2018;2018:750-3. https://doi.org/10.1109/EMBC. 2018.8512422.

34. Ha R, Chang P, Mema E, Mutasa S, Karcich J, Wynn RT, Liu MZ, Jambawalikar S. Fully Automated convolutional neural network method for quantification of breast MRI fibroglandular tissue and background parenchymal enhancement. J Digit Imaging. 2019;32(1):141-7. https://doi.org/10.1007/s10278-018-01147.

35. Tomida T, Urikura A, Uematsu T, Shirata K, Nakaya Y. Contrast enhancement in breast cancer and background mammary-gland tissue during the super-early phase of dynamic breast magnetic resonance imaging. Acad Radiol. 2017;24(11):1380-6. https:// doi.org/10.1016/j.acra.2017.05.018

36. Honda M, Kataoka M, Iima M, Miyake KK, Ohashi A, Kishimoto AO, Ota R, Nickel MD, Toi M, Togashi K. Background parenchymal enhancement and its effect on lesion detectability in ultrafast dynamic contrast-enhanced MRI. Eur J Radiol. 2020;129:108984. https://doi.org/10.1016/j.ejrad.2020.108984.

37. Kim SY, Cho N, Choi Y, Shin SU, Kim ES, Lee SH, Chang JM, Moon WK. Ultrafast dynamic contrast-enhanced breast MRI: Lesion conspicuity and size assessment according to background parenchymal enhancement. Korean J Radiol. 2020;21(5):561-71. https://doi.org/10.3348/kjr.2019.0567.

38. Pineda FD, Medved M, Wang S, Fan X, Schacht DV, Sennett C, Oto A, Newstead GM, Abe H, Karczmar GS. Ultrafast bilateral DCE-MRI of the breast with conventional fourier sampling: preliminary evaluation of semi-quantitative analysis. Acad Radiol. 2016;23(9):1137-44. https://doi.org/10.1016/j.acra.2016. 04.008.

39. Shiraishi M, Igarashi T, Terayama T, Watanabe K, Ashida $H$, Ojiri H. Breast magnetic resonance imaging for estimation of the tumour extent in patients with pure ductal carcinoma in situ: comparison between full diagnostic and abbreviated protocols. Eur J Radiol. 2020;123:108788. https://doi.org/10.1016/j.ejrad. 2019.108788.

40. •Watt GP, Sung J, Morris EA, Buys SS, Bradbury AR, Brooks JD, Conant EF, Weinstein SP, Kontos D, Woods M, Colonna SV, Liang $\mathrm{X}$, Stein MA, Pike MC, Bernstein JL. Association of breast cancer with MRI background parenchymal enhancement: the IMAGINE case-control study. Breast Cancer Res. 2020;22(1):138. https://doi. org/10.1186/s13058-020-01375-7. This study demonstrated an association between moderate or marked BPE and premenopausal breast cancer after adjusting for multiple risk factors and confounders.

41. •Arasu VA, Miglioretti DL, Sprague BL, Alsheik NH, Buist DSM, Henderson LM, Herschorn SD, Lee JM, Onega T, Rauscher GH, Wernli KJ, Lehman CD, Kerlikowske K. Populationbased assessment of the association between magnetic resonance imaging background parenchymal enhancement and future primary breast cancer risk. J Clin Oncol. 2019;37(12):954-963. https://doi.org/10.1200/JCO.18.00378. This study demonstrated an association between BPE and future breast cancer risk independent of breast density.

42. Hu N, Zhao J, Li Y, Fu Q, Zhao L, Chen H, Qin W, Yang G. Breast cancer and background parenchymal enhancement at breast magnetic resonance imaging: a meta-analysis. BMC Med Imaging. 2021;21(1):32. https://doi.org/10.1186/s12880-02100566-8.

43. Zhang H, Guo L, Tao W, Zhang J, Zhu Y, Abdelrahim MEA, Bai G. Possible breast cancer risk related to background parenchymal enhancement at breast MRI: a meta-analysis study. Nutr Cancer. 2021;73(8):1371-7. $\quad$ https://doi.org/10.1080/01635581.2020. 1795211.

44. Saha A, Grimm LJ, Ghate SV, Kim CE, Soo MS, Yoon SC, Mazurowski MA. Machine learning-based prediction of future breast cancer using algorithmically measured background parenchymal enhancement on high-risk screening MRI. J Magn Reson Imaging. 2019;50(2):456-64. https://doi.org/10.1002/jmri. 26636.

45. -Thompson CM, Mallawaarachchi I, Dwivedi DK, Ayyappan AP, Shokar NK, Lakshmanaswamy R, Dwivedi AK. The association of background parenchymal enhancement at breast MRI with breast cancer: a systematic review and meta-analysis. Radiology. 2019;292(3):552-561. https://doi.org/10.1148/radiol.2019182441. Systematic review and meta-analysis showing that higher BPE is associated with the presence of breast cancer in women with an elevated lifetime risk of breast cancer but not in women with average risk.

46. Grimm LJ, Saha A, Ghate SV, Kim C, Soo MS, Yoon SC, Mazurowski MA. Relationship between background parenchymal enhancement on high-risk screening MRI and future breast cancer risk. Acad Radiol. 2019;26(1):69-75. https://doi.org/10.1016/j. acra.2018.03.013.

47. Bermot C, Saint-Martin C, Malhaire C, Sebbag-Sfez D, MouretFourme E, Carton M, Thibault FE. Background parenchymal enhancement and fibroglandular tissue on breast MRI in women with high genetic risk: are changes before and after risk-reducing 
salpingo-oophorectomy associated with breast cancer risk? Eur J Radiol. 2018;109:171-7. https://doi.org/10.1016/j.ejrad.2018.10. 030 .

48. DeLeo MJ 3rd, Domchek SM, Kontos D, Conant E, Chen J, Weinstein S. Breast MRI fibroglandular volume and parenchymal enhancement in BRCA1 and BRCA2 mutation carriers before and immediately after risk-reducing salpingo-oophorectomy. AJR Am J Roentgenol. 2015;204(3):669-73. https://doi.org/10.2214/ AJR.13.12146.

49. Kim GR, Cho N, Kim SY, Han W, Moon WK. Interval cancers after negative supplemental screening breast MRI results in women with a personal history of breast cancer. Radiology. 2021;300(2):314-23. https://doi.org/10.1148/radiol.2021203074.

50. Liu K, Zhang W, Dai Z, Wang M, Tian T, Liu X, Kang H, Guan $\mathrm{H}$, Zhang S, Dai Z. Association between body mass index and breast cancer risk: evidence based on a dose-response metaanalysis. Cancer Manag Res. 2018;18(10):143-51. https://doi. org/10.2147/CMAR.S144619.

51. Tchernof A, Després JP. Pathophysiology of human visceral obesity: an update. Physiol Rev. 2013;93(1):359-404. https://doi. org/10.1152/physrev.00033.2011.

52. Brown JC, Kontos D, Schnall MD, Wu S, Schmitz KH. The doseresponse effects of aerobic exercise on body composition and breast tissue among women at high risk for breast cancer: a randomized trial. Cancer Prev Res (Phila). 2016;9(7):581-8. https://doi.org/10.1158/1940-6207.CAPR-15-0408.

53. An YS, Jung Y, Kim JY, Han S, Kang DK, Park SY, Kim TH. Metabolic activity of normal glandular tissue on ${ }^{18}$ F-fluorodeoxyglucose positron emission tomography/computed tomography: correlation with menstrual cycles and parenchymal enhancements. J Breast Cancer. 2017;20(4):386-92. https://doi. org/10.4048/jbc.2017.20.4.386.

54. Mema E, Mango VL, Guo X, Karcich J, Yeh R, Wynn RT, Zhao B, Ha RS. Does breast MRI background parenchymal enhancement indicate metabolic activity? qualitative and 3D quantitative computer imaging analysis. J Magn Reson Imaging. 2018;47(3):753-9. https://doi.org/10.1002/jmri.25798.

55. Choi BB, Kim SH, Park CS, Jung NY. Correlation of prognostic factors of invasive lobular carcinoma with ADC value of DWI and SUVMax of FDG-PET. Chonnam Med J. 2017;53(2):133-9. https://doi.org/10.4068/cmj.2017.53.2.133.

56. Leithner D, Baltzer PA, Magometschnigg HF, Wengert GJ, Karanikas G, Helbich TH, Weber M, Wadsak W, Pinker K. Quantitative assessment of breast parenchymal uptake on 18FFDG PET/CT: correlation with age, background parenchymal enhancement, and amount of fibroglandular tissue on MRI. J Nucl Med. 2016;57(10):1518-22. https://doi.org/10.2967/jnumed.116. 174904

57. • Sippo DA, Rutledge GM, Mercaldo SF, Burk KS, Edmonds CE, Dang PA, Lehman CD. Impact of background parenchymal enhancement on diagnostic performance in screening breast MRI. Acad Radiol. 2020;27(5):663-671. https://doi.org/10.1016/j.acra. 2019.06.020. This study found that moderate or marked BPE on screening MRI resulted in a higher abnormal interpretation rate but did not significantly impact other performance metrics including cancer detection rate.

58. Preibsch H, Beckmann J, Pawlowski J, Kloth C, Hahn M, Staebler A, Wietek BM, Nikolaou K, Wiesinger B. Accuracy of breast magnetic resonance imaging compared to mammography in the preoperative detection and measurement of pure ductal carcinoma in situ: a retrospective analysis. Acad Radiol. 2019;26(6):760-5. https://doi.org/10.1016/j.acra.2018.07.013.

59. •Ray KM, Kerlikowske K, Lobach IV, Hofmann MB, Greenwood HI, Arasu VA, Hylton NM, Joe BN. Effect of background parenchymal enhancement on breast MR Imaging interpretive performance in community-based practices. Radiology.
2018;286(3):822-829. https://doi.org/10.1148/radiol.2017170811. This study found that moderate or marked BPE was associated with higher abnormal interpretation rate, higher biopsy rate, and lower specificity with no difference in cancer detection rate.

60. Kim SY, Lee HS, Kim EK, Kim MJ, Moon HJ, Yoon JH. Effect of background parenchymal enhancement on pre-operative breast magnetic resonance imaging: how it affects interpretation and the role of second-look ultrasound in patient management. Ultrasound Med Biol. 2016;42(12):2766-74. https://doi.org/10.1016/j. ultrasmedbio.2016.08.008.

61. Taron J, Fleischer S, Preibsch H, Nikolaou K, Gruber I, Bahrs S. Background parenchymal enhancement in pregnancy-associated breast cancer: a hindrance to diagnosis? Eur Radiol. 2019;29(3):1187-93. https://doi.org/10.1007/s00330-018-5721-7.

62. Oh SW, Lim HS, Moon SM, Kim JW, Shin SS, Heo SH, Lee JS, Park MH. MR imaging characteristics of breast cancer diagnosed during lactation. Br J Radiol. 2017;90(1078):20170203. https:// doi.org/10.1259/bjr.20170203.

63. Yoon J, Kim EK, Kim MJ, Moon HJ, Yoon JH, Park VY. Preoperative magnetic resonance imaging features associated with positive resection margins in patients with invasive lobular carcinoma. Korean J Radiol. 2020;21(8):946-54. https://doi.org/10. 3348/kjr.2019.0674.

64. Preibsch H, Richter V, Bahrs SD, Hattermann V, Wietek BM, Bier G, Kloth C, Blumenstock G, Hahn M, Staebler A, Nikolaou $\mathrm{K}$, Wiesinger B. Repeated surgeries in invasive lobular breast cancer with preoperative MRI: role of additional carcinoma in situ and background parenchymal enhancement. Eur J Radiol. 2017;90:181-7. https://doi.org/10.1016/j.ejrad.2017.02.045.

65. Bae MS, Bernard-Davila B, Sung JS, Morris EA. Preoperative breast MRI features associated with positive or close margins in breast-conserving surgery. Eur J Radiol. 2019;117:171-7. https:// doi.org/10.1016/j.ejrad.2019.06.011.

66. Lim Y, Ko ES, Han BK, Ko EY, Choi JS, Lee JE, Lee SK. Background parenchymal enhancement on breast MRI: association with recurrence-free survival in patients with newly diagnosed invasive breast cancer. Breast Cancer Res Treat. 2017;163(3):573-86. https://doi.org/10.1007/s10549-017-4217-5.

67. Park G, Bae K, Hwang IY, Kim JS, Kwon WJ, Bang M. Prediction of residual malignancy after excisional biopsy for breast cancer with suspicious microcalcifications: comparison of mammography and magnetic resonance imaging. Clin Breast Cancer. 2019;19(6):e753-8. https://doi.org/10.1016/j.clbc.2019.05.003.

68. Baek SH, Choi WJ, Cha JH, Kim HH, Shin HJ, Chae EY. Comparison of mammography, ultrasound, and MRI in size assessment of ductal carcinoma in situ with histopathologic correlation. Acta Radiol. 2017;58(12):1434-41. https://doi.org/ 10.1177/0284185117698860.

69. Choi WJ, Cha JH, Kim HH, Shin HJ, Chae EY. The accuracy of breast MR imaging for measuring the size of a breast cancer: analysis of the histopathologic factors. Clin Breast Cancer. 2016;16(6):e145-52. https://doi.org/10.1016/j.clbc.2016.07.007.

70. •Rella R, Contegiacomo A, Bufi E, Mercogliano S, Belli P, Manfredi R. Background parenchymal enhancement and breast cancer: a review of the emerging evidences about its potential use as imaging biomarker. Br J Radiol. 2021;94(1119):20200630. https://doi.org/10.1259/bjr.20200630. Systemic review on BPE as an imaging biomarker.

71. Kim SY, Cho N, Choi Y, Lee SH, Ha SM, Kim ES, Chang JM, Moon WK. Factors affecting pathologic complete response following neoadjuvant chemotherapy in breast cancer: development and validation of a predictive nomogram. Radiology. 2021;299(2):290-300. https://doi.org/10.1148/radiol.2021203871.

72. Kim SY, Cho N, Shin SU, Lee HB, Han W, Park IA, Kwon BR, Kim SY, Lee SH, Chang JM, Moon WK. Contrast-enhanced MRI after neoadjuvant chemotherapy of breast cancer: lesion-to- 
background parenchymal signal enhancement ratio for discriminating pathological complete response from minimal residual tumour. Eur Radiol. 2018;28(7):2986-95. https://doi.org/10. 1007/s00330-017-5251-8.

73. Arasu VA, Kim P, Li W, Strand F, McHargue C, Harnish R, Newitt DC, Jones EF, Glymour MM, Kornak J, Esserman LJ, Hylton NM, ISPY2 investigators. Predictive value of breast MRI background parenchymal enhancement for neoadjuvant treatment response among HER2- patients. J Breast Imaging. 2020;2(4):352-60. https://doi.org/10.1093/jbi/wbaa028.

74. You C, Gu Y, Peng W, Li J, Shen X, Liu G, Peng W. Decreased background parenchymal enhancement of the contralateral breast after two cycles of neoadjuvant chemotherapy is associated with tumor response in HER2-positive breast cancer. Acta Radiol. 2018;59(7):806-12. https://doi.org/10.1177/0284185117738560.

75. You C, Peng W, Zhi W, He M, Liu G, Xie L, Jiang L, Hu X, Shen $\mathrm{X}, \mathrm{Gu} \mathrm{Y}$. Association between background parenchymal enhancement and pathologic complete remission throughout the neoadjuvant chemotherapy in breast cancer patients. Transl Oncol. 2017;10(5):786-92. https://doi.org/10.1016/j.tranon.2017. 07.005 .

76. Dong JM, Wang HX, Zhong XF, Xu K, Bian J, Feng Y, Chen L, Zhang L, Wang X, Ma DJ, Wang B. Changes in background parenchymal enhancement in HER2-positive breast cancer before and after neoadjuvant chemotherapy: association with pathologic complete response. Medicine (Baltimore). 2018;97(43):e12965. https://doi.org/10.1097/MD.0000000000012965.

77. Moliere S, Oddou I, Noblet V, Veillon F, Mathelin C. Quantitative background parenchymal enhancement to predict recurrence after neoadjuvant chemotherapy for breast cancer. Sci Rep. 2019;9(1):19185. https://doi.org/10.1038/s41598-019-55820-5.

78. Oh SJ, Chae EY, Cha JH, Shin HJ, Choi WJ, Kim HH. Relationship between background parenchymal enhancement on breast MRI and pathological tumor response in breast cancer patients receiving neoadjuvant chemotherapy. $\mathrm{Br} \mathrm{J}$ Radiol. 2018;91(1088):20170550. https://doi.org/10.1259/bjr.20170550.

79. Hilal T, Covington M, Kosiorek HE, Zwart C, Ocal IT, Pockaj BA, Northfelt DW, Patel BK. Breast MRI phenotype and background parenchymal enhancement may predict tumor response to neoadjuvant endocrine therapy. Breast J. 2018;24(6):1010-4. https://doi.org/10.1111/tbj.13101.

80. Zhang M, Sadinski M, Haddad D, Bae MS, Martinez D, Morris EA, Gibbs P, Sutton EJ. Background parenchymal enhancement on breast MRI as a prognostic surrogate: correlation with breast cancer oncotype Dx score. Front Oncol. 2021;4(10):595820. https://doi.org/10.3389/fonc.2020.595820.

81. Bae MS, Chang JM, Cho N, Han W, Ryu HS, Moon WK. Association of preoperative breast MRI features with locoregional recurrence after breast conservation therapy. Acta Radiol. 2018;59(4):409-17. https://doi.org/10.1177/0284185117723041.

82. Choi EJ, Choi H, Choi SA, Youk JH. Dynamic contrast-enhanced breast magnetic resonance imaging for the prediction of early and late recurrences in breast cancer. Medicine (Baltimore). 2016; 95(48):e5330. https://doi.org/10.1097/MD.0000000000005330.

83. Luo J, Johnston BS, Kitsch AE, Hippe DS, Korde LA, Javid S, Lee JM, Peacock S, Lehman CD, Partridge SC, Rahbar H. Ductal carcinoma in situ: quantitative preoperative breast $\mathrm{mr}$ imaging features associated with recurrence after treatment. Radiology. 2017;285(3):788-97. https://doi.org/10.1148/radiol.2017170587.

84. Choi JS, Ko ES, Ko EY, Han BK, Nam SJ. Background parenchymal enhancement on preoperative magnetic resonance imaging: association with recurrence-free survival in breast cancer patients treated with neoadjuvant chemotherapy. Medicine (Baltimore). 2016;95(9):e3000. https://doi.org/10.1097/MD. 0000000000003000
85. Lo Gullo R, Daimiel I, Rossi Saccarelli C, Bitencourt A, Sevilimedu V, Martinez DF, Jochelson MS, Morris EA, Reiner JS, Pinker K. MRI background parenchymal enhancement, fibroglandular tissue, and mammographic breast density in patients with invasive lobular breast cancer on adjuvant endocrine hormonal treatment: associations with survival. Breast Cancer Res. 2020;22(1):93. https://doi.org/10.1186/s13058-020-01329-z.

86. Lee YJ, Youn IK, Kim SH, Kang BJ, Park WC, Lee A. Triplenegative breast cancer: pretreatment magnetic resonance imaging features and clinicopathological factors associated with recurrence. Magn Reson Imaging. 2020;66:36-41. https://doi.org/10. 1016/j.mri.2019.10.001.

87. Ha R, Mango V, Al-Khalili R, Mema E, Friedlander L, Desperito E, Wynn RT. Evaluation of association between degree of background parenchymal enhancement on MRI and breast cancer subtype. Clin Imaging. 2018;51:307-10. https://doi.org/10.1016/ j.clinimag.2018.05.008.

88. Vreemann S, Gubern-Mérida A, Borelli C, Bult P, Karssemeijer N, Mann RM. The correlation of background parenchymal enhancement in the contralateral breast with patient and tumor characteristics of MRI-screen detected breast cancers. PLoS One. 2018;13(1):e0191399. https://doi.org/10.1371/journal.pone.0191399.

89. Öztürk M, Polat AV, Süllü Y, Tomak L, Polat AK. Background parenchymal enhancement and fibroglandular tissue proportion on breast MRI: correlation with hormone receptor expression and molecular subtypes of breast cancer. J Breast Health. 2017;13(1):27-33. https://doi.org/10.5152/tjbh.2016.3247.

90. Mema E, Schnabel F, Chun J, Kaplowitz E, Price A, Goodgal J, Moy L. The relationship of breast density in mammography and magnetic resonance imaging in women with triple negative breast cancer. Eur J Radiol. 2020;124:108813. https://doi.org/10.1016/j. ejrad.2020.108813.

91. Wu J, Sun X, Wang J, Cui Y, Kato F, Shirato H, Ikeda DM, Li R. Identifying relations between imaging phenotypes and molecular subtypes of breast cancer: model discovery and external validation. J Magn Reson Imaging. 2017;46(4):1017-27. https://doi. org/10.1002/jmri.25661.

92. Xu C, Yu J, Wu F, Li X, Hu D, Chen G, Wu G. High-background parenchymal enhancement in the contralateral breast is an imaging biomarker for favorable prognosis in patients with triplenegative breast cancer treated with chemotherapy. Am J Transl Res. 2021;13(5):4422-36.

93. Park VY, Kim EK, Kim MJ, Yoon JH, Moon HJ. Breast parenchymal signal enhancement ratio at preoperative magnetic resonance imaging: association with early recurrence in triplenegative breast cancer patients. Acta Radiol. 2016;57(7):802-8. https://doi.org/10.1177/0284185115609803.

94. Shin GW, Zhang Y, Kim MJ, Su MY, Kim EK, Moon HJ, Yoon JH, Park VY. Role of dynamic contrast-enhanced MRI in evaluating the association between contralateral parenchymal enhancement and survival outcome in ER-positive, HER2-negative, node-negative invasive breast cancer. J Magn Reson Imaging. 2018;48(6):1678-89. https://doi.org/10.1002/jmri.26176.

95. van der Velden BH, Dmitriev I, Loo CE, Pijnappel RM, Gilhuijs KG. Association between parenchymal enhancement of the contralateral breast in dynamic contrast-enhanced MR imaging and outcome of patients with unilateral invasive breast cancer. Radiology. 2015;276(3):675-85. https://doi.org/10.1148/radiol. 15142192.

Publisher's Note Springer Nature remains neutral with regard to jurisdictional claims in published maps and institutional affiliations. 